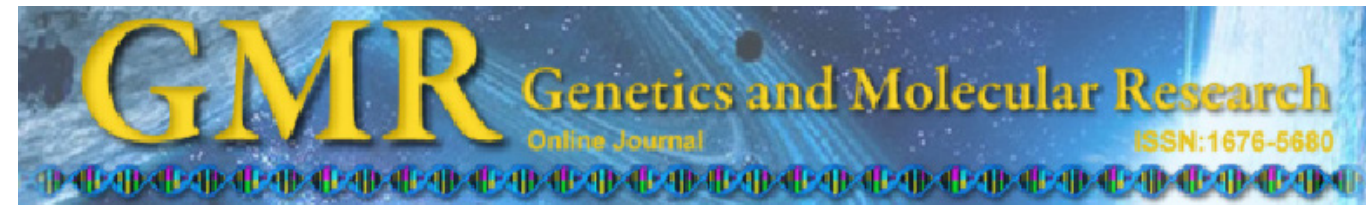

\title{
Estimation of genetic parameters for growth traits in a breeding program for rainbow trout (Oncorhynchus mykiss) in China
}

\author{
G. Hu, W. Gu, Q.L. Bai and B.Q. Wang \\ Heilongjiang River Fishery Research Institute, \\ Chinese Academy of Fishery Sciences, Harbin, China \\ Corresponding author: B.Q. Wang \\ E-mail:wbqfish@yahoo.com.cn
}

Genet. Mol. Res. 12 (2): 1457-1467 (2013)

Received August 9, 2012

Accepted January 7, 2013

Published April 26, 2013

DOI http://dx.doi.org/10.4238/2013.April.26.7

\begin{abstract}
Genetic parameters and breeding values for growth traits were estimated in the first and, currently, the only family selective breeding program for rainbow trout (Oncorhynchus mykiss) in China. Genetic and phenotypic data were collected for growth traits from 75 full-sibling families with a 2-generation pedigree. Genetic parameters and breeding values for growth traits of rainbow trout were estimated using the derivative-free restricted maximum likelihood method. The goodness-of-fit of the models was tested using Akaike and Bayesian information criteria. Genetic parameters and breeding values were estimated using the best-fit model for each trait. The values for heritability estimating body weight and length ranged from 0.20 to 0.45 and from 0.27 to 0.60 , respectively, and the heritability of condition factor was 0.34 . Our results showed a moderate degree of heritability for growth traits in this breeding program and suggested that the genetic and phenotypic tendency of body length, body weight, and condition factor were similar. Therefore, the selection of phenotypic values based on pedigree information was also suitable in this research population.
\end{abstract}

Key words: Rainbow trout; Genetic parameter; Breeding value; China 


\section{INTRODUCTION}

Rainbow trout (Oncorhynchus mykiss) originated in North America and was one of the first species of fish to be domesticated. The cultivation of rainbow trout has been distributed worldwide, making rainbow trout one of the most widely cultivated fishes (Gall and Crandell, 1992). A thorough understanding of the genetic control of growth traits in rainbow trout is key to genetic enhancements in production performance. On the basis of animal and plant breeding science, genetic improvement in aquaculture has been successfully implemented during the past three decades, particularly in salmonid farming, and is still in progress (Donaldson, 1969; Gall and Crandell, 1992; Janhunen et al., 2012; Kause et al., 2012; Sae-Lim et al., 2012). Coldwater fish culturing in China began in 1959, when eyed eggs and fry of rainbow trout were introduced from the Democratic People's Republic of Korea. Rainbow trout culture expanded rapidly throughout 22 provinces in China (Wang and Yang, 2002). According to statistical data provided by the Food and Agriculture Organization (2012), the production of rainbow trout in China was 16,397 tons in 2010. Because rainbow trout is the major cold-water fish farmed in China, accelerating selective breeding and preventing genetic degeneration are important, but the country has gotten a late start on this research. Programs have been established for 80 years in the United States, but the first selective breeding program for rainbow trout in China began in 2004 (Sun and Wang, 2010).

In 1978, the Bohai cold-water fish experimental station, which is affiliated with the Heilongjiang River Fishery Research Institute (HRFRI) of the Chinese Academy of Fishery Sciences became the center of rainbow trout culture studies in China (Wang and Yang, 2002). HRFRI has been conducting research and disseminating culture techniques for cold-water fish in collaboration with experts from Europe and Japan since the 1980s (Wang and Yang, 2002). In cooperation with the Finnish National Fisheries Innovation Centre, HRFRI established the first family breeding program in China for rainbow trout, which was based on passive integrated transponder tags at the Bohai cold-water fish experimental station in 2004 (Sun and Wang, 2010). Many estimations of genetic parameters and breeding values for growth traits have been published for rainbow trout, and previous genetic studies have revealed moderate levels of genetic variation for growth traits in salmon (Gunnes and Gjedrem, 1978; Gjerde and Gjedrem, 1984; Gjerde et al., 1994; Rye and Gjerde, 1996; Gjedrem, 1983, 2000), but they vary greatly among experiments (e.g., ranging from 0 to 0.58 for weight). Thus, a genetic estimation for growth traits in the breeding program for rainbow trout is needed for the common trout-farming environment in China.

In this study, we aimed to estimate genetic parameters and breeding values for growth traits in the first and, currently, the only family breeding program for rainbow trout in China. Genetic and phenotypic data were collected for growth traits from 75 full-sibling families with a 2-generation pedigree. Genetic parameters and breeding values for growth traits of rainbow trout were estimated using the derivative-free restricted maximum likelihood (DFREML) method.

\section{MATERIAL AND METHODS}

\section{Data collection}

Samples were obtained from the rainbow trout breeding program at the Bohai cold- 
water fish experimental station affiliated with HRFRI of the Chinese Academy of Fishery Sciences. Five cultured strains, established in 2001, including the Bohai, Denmark, Norway, American Donaldson, and California strains, were used to create the basic populations [generation $0\left(\mathrm{G}_{0}\right)$ ]. The Bohai strain originated with the first introduction of rainbow trout from North Korean in 1959. The Demark and other strains were introduced from Denmark, Norway, and the United States, respectively. Four-year-old fish from these strains were used in a complete diallel cross and a self-breeding experiment in 2004 (Griffing, 1956). The offspring from the $\mathrm{G}_{0}$ population, as the first generation $\left(\mathrm{G}_{1}\right)$, were cultivated in a natural flowing spring at a temperature ranging from $5.2^{\circ}$ to $16.0^{\circ} \mathrm{C}$ at the Bohai experimental station. The parental fish were cultured in earth pond with $15 \mathrm{~m}$ in width, $120 \mathrm{~m}$ in length, and $0.8 \mathrm{~m}$ in water depth, water flow of 20-30 L/s, and dissolved oxygen saturation range from 42 to $80 \%$. All the fish were fed by manual work in the experiment, the feeding rate per day depends on the water temperature and dissolved oxygen saturation according to "The Feed Catalogue For Trout from BioMar Company".

Seventy-five male and 75 female fish from $\mathrm{G}_{1}$ were used between October 2007 and January 2008 to establish 75 full-sibling $\mathrm{G}_{2}$ families. After floating until March 2008, all fry were reared in the aquarium for 10 months until reaching the size when could be implanted the passive-integrated transponder tag, the aquarium with $1 \mathrm{~m}$ in diameter, $0.5 \mathrm{~m}$ in water depth, in which there was average water temperature range from 6.5 to 12 , water flow of $6-8 \mathrm{~L} / \mathrm{min}$. During 10 months rearing, there were 3 times for randomly screened for fish in order to satisfy the environmental requirement for the fry in the aquarium.

When average body weight reached $>50 \mathrm{~g}$, we selected 50 fish with no deformity and defeature from each tank and mixed them in a cemented pool after implanting passiveintegrated transponder tags to avoid the influence of environmental factors on the cross. The concrete pond with flow through spring water, water flow of $20-30 \mathrm{~L} / \mathrm{s}, 5 \mathrm{~m}$ in width, $30 \mathrm{~m}$ in length, and $0.7 \mathrm{~m}$ in water depth. Body length and body weight were measured three times for each fish during 2009 and 2010. The condition factors (CFs) were calculated for all fish: $\mathrm{CF}=$ ungutted body weight / (body length) ${ }^{3} \times 100 \%$. After the abnormal and wrong records were deleted, the $\mathrm{G}_{2}$ consisted of 2157 individuals; each fish had 3 records made at 1, 1.5, and 2 years of age.

\section{Statistical model}

Simple descriptive statistics for data collected are summarized in Table 1. The selection of fixed effects fitted to the model was carried out using the general linear model procedure of SAS (SAS Institute, Cary, NC, USA). All possible interactions among fixed effects were tested. Fixed effects with a $\mathrm{P}$ value of $>0.05$ were excluded from the final model. Significant fixed effects on body weight and body length included year, season, sire, dam, and water temperature. The fixed effect of CF excluded temperature from the model owing to statistical insignificance. Variance components and heritability for each trait were estimated for a single trait, two traits, and a repeatability animal model using DFREML with a simplex algorithm using multiple-trait DFREML (Boldman et al., 1995). 


\begin{tabular}{|c|c|c|c|c|c|}
\hline Traits & Mean & SD & Minimum & Maximum & $\mathrm{CV}$ \\
\hline Weight $_{(1 \text { year) }}$ & 63.014 & 34.269 & 51 & 150 & 0.544 \\
\hline Weight $_{(1.5 \text { year })}$ & 176.41 & 41.993 & 121 & 330 & 0.238 \\
\hline Weight $_{(2 \text { years })}$ & 624.467 & 129.923 & 238.5 & 1090 & 0.208 \\
\hline Length & 15.485 & 7.467 & 13.75 & 88 & 0.482 \\
\hline Length $_{(1.5 \text { year })}$ & 24.105 & 7.654 & 15.1 & 50.4 & 0.318 \\
\hline Length $_{(2 \text { years })}$ & 35.869 & 9.182 & 16.1 & 54.01 & 0.256 \\
\hline $\mathrm{CF}_{(1 \text { year })}$ & 0.9293 & 0.4672 & 0.442 & 1.899 & 0.503 \\
\hline $\mathrm{CF}_{(1.5 \text { year) }}^{(1(\text { year) }}$ & 1.0957 & 0.9714 & 0.345 & 1.91 & 0.8865 \\
\hline $\mathrm{CF}_{(2 \text { years })}$ & 1.6278 & 2.462 & 0.28 & 2.85 & 1.512 \\
\hline
\end{tabular}

The single-trait animal model (model I) used is as follows:

$$
y_{i j k l}=u+\mathrm{E}_{i}+s_{j}+d_{k}+a+e_{i j k l}
$$

(Equation 1)

where $y_{i j k l}$ is the observation in individual animals, $\mu$ is the population mean, $E_{i}$ is the fixed effect of common environmental effects including year and season, $s_{j}$ is the fixed effect of dam family, $d_{k}$ is the fixed effect of sire family, $a$ is the random animal effect, and $e_{i j k l}$ is the random residual error for animal individual.

The matrix notation is as follows:

$$
Y=X b+Z a+e
$$

(Equation 2)

where $Y$ is a vector of phenotype observations of animals, $a$ is a vector of random breeding values, $b$ is a vector of the fixed effects of the common environmental effect dam family and sire family, $X$ and $Z$ are the corresponding incidence matrices relating the effects to $Y$, and $e$ is the vector of random residuals.

Then, $E(y)=X b, E(a)=0, E(e)=0 \quad \operatorname{Var}\left[\begin{array}{l}a \\ e\end{array}\right]=\left[\begin{array}{cc}A \delta_{a}^{2} & 0 \\ & \\ 0 & I \delta_{e}^{2}\end{array}\right]$ (Equation 3)

If $A$ is the matrix of additive genetic relationships among individuals, the mixed model equation (MME) used is as follows:

$$
\left[\begin{array}{ll}
X^{\prime} X & X^{\prime} Z \\
Z^{\prime} X & Z^{\prime} Z+A^{-1} k
\end{array}\right]\left[\begin{array}{l}
\hat{b} \\
\hat{a}
\end{array}\right]=\left[\begin{array}{l}
X^{\prime} y \\
Z^{\prime} y
\end{array}\right]
$$

(Equation 4) 
The multiple-trait animal model (model II) is as follows:

$$
y_{t i j k l}=\mu+\mathrm{E}_{t i}+s_{t j}+d_{t k}+a+e_{t i j k l}
$$

where $t$ represents the traits of body weight, body length, and condition factor, $y_{t i j k l}$ is the observation of trait $t$ for individual animals, and other definitions are the same as those described for the single-trait animal model.

The MME is as follows:

$$
\left[\begin{array}{cccc}
X_{1}^{\prime} X_{1} r^{11} & X_{1}^{\prime} X_{2} r^{12} & X_{1}^{\prime} Z_{1} r^{11} & X_{1}^{\prime} Z_{2} r^{12} \\
X_{2}^{\prime} X_{1} r^{12} & X_{2}^{\prime} X_{2} r^{22} & X_{2}^{\prime} Z_{1} r^{12} & X_{2}^{\prime} Z_{2} r^{22} \\
Z_{1}^{\prime} X_{1} r^{11} & Z_{1}^{\prime} X_{2} r^{12} & Z_{1}^{\prime} Z_{1} r^{11}+A^{-1} g^{11} & Z_{1}^{\prime} Z_{2} r^{12}+A^{-1} g^{12} \\
Z_{2}^{\prime} X_{1} r^{12} & Z_{2}^{\prime} X_{2} r^{22} & Z_{2}^{\prime} Z_{1} r^{12}+A^{-1} g^{12} & Z_{2}^{\prime} Z_{2} r^{22}+A^{-1} g^{22}
\end{array}\right]\left[\begin{array}{c}
\hat{b_{1}} \\
\hat{b_{2}} \\
\hat{a_{1}} \\
\hat{a_{2}}
\end{array}\right]=\left[\begin{array}{c}
X_{1}^{\prime} y_{1} r^{11}+X_{1}^{\prime} y_{2} r^{12} \\
X_{2}^{\prime} y_{2} r^{12}+X_{2}^{\prime} y_{2} r^{22} \\
Z_{1}^{\prime} y_{1} r^{11}+Z_{1}^{\prime} y_{2} r^{12} \\
Z_{2}^{\prime} y_{2} r^{12}+Z_{2}^{\prime} y_{2} r^{22}
\end{array}\right] \text { (Equation 6) }
$$

The repeatability animal model (model III) is as follows:

$$
y_{i j k l}=u+\mathrm{E}_{i}+s_{j}+d_{k}+a+p+e_{i j k l}
$$

(Equation 7)

where $p$ is the permanent environment effect. Other symbols are the same as those described for the single-trait animal model.

The MME is as follows:

$$
\left[\begin{array}{lll}
X & X^{\prime} Z & X^{\prime} W \\
Z X & Z^{\prime} Z+A^{-1} k_{2} & Z^{\prime} W \\
W^{\prime} X & W^{\prime} Z & W^{\prime} W+A^{-1} k_{2}
\end{array}\right]\left[\begin{array}{l}
\hat{b} \\
\hat{a} \\
\hat{p}
\end{array}\right]=\left[\begin{array}{l}
X^{\prime} y \\
W^{\prime} y \\
W^{\prime} y
\end{array}\right]
$$

\section{Estimation of genetic parameters and breeding values}

Calculations were carried out with the multiple-trait DFREML (Boldman et al., 1995), a set of programs using the simplex procedure to locate the maximum of the log of likelihood. Convergence was considered to have been reached when the variance of function values in the simplex was less than $10^{-9}$. Variance and heritability for each trait were estimated for three animal models using DFREML with a simplex algorithm. Phenotypic and genetic correlations were estimated using a multivariate linear model. To calculate genetic trends, breeding values across generations were estimated with the best linear unbiased prediction method by using the repeatability animal model. Means of animal estimated breeding values were regressed across years to predict annual genetic trends for growth traits. 


\section{Model selection}

To test the goodness-of-fit among the three models, Akaike information criterion (AIC) and Bayesian information criterion (BIC) were chosen to determine the optimal models. The AIC and BIC were also chosen because likelihood ratio tests tend to favor models with multiple parameters (Jensen, 2001), whereas these criteria penalize models with many parameters.

AIC and BIC were defined as

$$
\mathrm{AIC}=-2 \log (\mathrm{Li})+2 \mathrm{t}_{\mathrm{i}}, \text { and } \mathrm{BIC}=-2 \log (\mathrm{Li})+\mathrm{t}_{\mathrm{i}} \log (\mathrm{v}) \quad(\text { Equation } 9)
$$

where $t_{i}$ is the number of variance parameters in the model $\mathrm{i}$, and $\mathrm{v}=\mathrm{n}-\mathrm{p}$ is the number of residual degrees of freedom. AIC and BIC were calculated for each model, and the model with the lowest value was assumed to be optimal.

\section{RESULTS}

\section{Parameter selection for models}

The importance of including particular fixed effects in our model is accommodated by F-tests. For growth traits, the effects of season, sire family, dam family, year, and temperature were highly significant $(\mathrm{P}<0.001)$, and they were therefore included in the model (Table 2$)$. In fact, the effects of season, year, and temperature were highly consistent and were considered a common environmental effect.

\begin{tabular}{|c|c|c|c|c|c|c|c|c|c|}
\hline \multirow[t]{2}{*}{ Factor } & \multicolumn{3}{|c|}{ Weight (g) } & \multicolumn{3}{|c|}{ Length $(\mathrm{cm})$} & \multicolumn{3}{|c|}{$\mathrm{CF}$} \\
\hline & MS & d.f. & $\mathrm{F}$ & MS & d.f. & $\mathrm{F}$ & MS & d.f. & $\mathrm{F}$ \\
\hline Year & 271233007.9 & 1 & $7133.06^{* *}$ & 308041.637 & 1 & $7382.39 * *$ & 625.1064 & 1 & 2.88 \\
\hline Season & 327319616.6 & 2 & $54945.6^{* *}$ & 276658.374 & 2 & $13401.6^{* *}$ & 773.5372 & 2 & $3.57 *$ \\
\hline Sire family & 535690.602 & 4 & $8.85^{* *}$ & 948.753844 & 4 & $14.12 * *$ & 510.2611 & 4 & $2.35^{*}$ \\
\hline Year $\mathrm{x}$ sire & 30425712.8 & 9 & $804.22 * *$ & 312216.886 & 9 & $837.84 * *$ & 411.711 & 9 & $1.90^{*}$ \\
\hline Season $\mathrm{x}$ sire & 46983586.9 & 14 & $8241.31 * *$ & 39844.0426 & 14 & $1910.25 * *$ & 551.084 & 14 & $2.54 * *$ \\
\hline Dam family & 591690.396 & 4 & $9.78 * *$ & 634.34382 & 4 & $9.43 * *$ & 187.366 & 4 & $0.86^{*}$ \\
\hline Year x dam & 30454425.0 & 9 & $805.44 * *$ & 34520.1045 & 9 & $831.14 * *$ & 190.428 & 9 & 0.88 \\
\hline Season $\mathrm{x}$ dam & 47022682.2 & 14 & $8315.01 * *$ & 39733.331 & 14 & $1893.16^{* *}$ & 266.323 & 14 & 1.23 \\
\hline Sire $\mathrm{x}$ dam & 312.185 .83 & 19 & $5.18 * *$ & 487.7671 & 19 & $7.30 * *$ & 228.215 & 19 & 1.05 \\
\hline Temperature & 25575145.6 & 2 & $52100.4^{* *}$ & 275505.82 & 2 & $12870.3^{* *}$ & 574.386 & 2 & 2.48 \\
\hline Year temperature & 2171404.17 & 3 & $34871.6^{* *}$ & 183862.874 & 3 & $86707.87 * *$ & 516.5411 & 3 & 2.38 \\
\hline Season temperature & 163686266.7 & 4 & $27513.5^{* *}$ & 138333.741 & 4 & $6520.40 * *$ & 387.5155 & 4 & 1.79 \\
\hline
\end{tabular}

$\mathrm{CF}=$ condition factors; $\mathrm{MS}=$ mean square values; d.f. $=$ degrees of freedom. ${ }^{*} \mathrm{P}<0.05 . * * \mathrm{P}<0.01$.

\section{Model selection}

The model selection results for AIC and BIC are presented in Table 3. AIC and BIC rank models and the models with the lowest values are the preferred models. Results indicate that for body weight, model I was superior to models II or III (rank I > II > III); for length, 
model II was superior (rank II > I > III); and only for CF did model III have the lowest scores $($ rank III > II > I).

Table 3. Estimates of Akaike information criterion (AIC) and Bayesian information criterion (BIC) comparing different models across different growth traits.

\begin{tabular}{llcccc}
\hline Trait & Model & Number of parameter & Log & AIC & BIC \\
\hline \multirow{2}{*}{ Weight } & Model I & 5 & 4.795 & 0.77 & 8.459521 \\
& Model II & 5 & 4.340 & 1.96 & 9.369562 \\
& Model III & 5 & 4.556 & 0.88 & 8.937264 \\
Length & Model I & 5 & 3.223 & 3.90 & 11.60212 \\
& Model II & 5 & 3.981 & 2.68 & 10.08662 \\
& Model III & 5 & 2.065 & 5.87 & 11.832703 \\
CF & Model I & 5 & 3.107 & 4.44 & 10.91803 \\
& Model II & 5 & 3.565 & 3.51 & 10.89201 \\
\hline
\end{tabular}

$\mathrm{CF}=$ condition factors

\section{Genetic parameters}

The genetic parameter of body weight estimated using the single-trait animal model showed moderate heritability estimates ranging from 0.2 to 0.45 . The genetic parameter of body length was estimated using the 2-trait animal model and showed slightly higher heritability estimates ranging from 0.27 to 0.60 . CF exhibited moderate heritability, with a value of 0.34 , and the repeatability of $\mathrm{CF}$, which was the breeding evaluation of individuals, was 0.35 . The variance components and heritability on the observed scale for these three traits are shown in Table 4.

Table 4. Variance component and heritability for body weight, body length and condition factors (CF).

\begin{tabular}{lccccc}
\hline Traits & $\mathrm{V}_{\mathrm{A}}$ & $\mathrm{V}_{\mathrm{PE}}$ & $\mathrm{V}_{\mathrm{R}}$ & $\mathrm{h}^{2}$ & Genetic model \\
\hline Weight $_{(1 \text { year }}$ & 27.912 & 33.752 & 61.65 & $0.45 \pm 0.03$ & Model I \\
Weight $_{(1.5 \text { year })}$ & 4770.85 & 6324.15 & 11094.66 & $0.41 \pm 0.02$ & Model I \\
Weight $_{(\text {2 years) }}$ & 5952.72 & 23454.8 & 29407.6 & $0.20 \pm 0.05$ & Model I \\
Length $_{(1 \text { year })}$ & 196.262 & 127.13 & 323.399 & $0.60 \pm 0.01$ & Model II \\
Length $_{(1.5 \text { year })}$ & 6437.05 & 4422.42 & 10859.4 & $0.54 \pm 0.02$ & Model II \\
Length $_{(2 \text { years }}$ & 3.83 & 30.28 & 34.218 & $0.27 \pm 0.04$ & Model II \\
CF & 72.28 & 2.208 & 140.92 & $0.34 \pm 0.02$ & Model III \\
\hline
\end{tabular}

\section{Phenotypic and genetic correlations}

Phenotypic correlation among body weight, body length, and CF of 1-year-old fish was positive and high. This finding was similar to that of the genetic correlations. Phenotypic correlation among the growth traits of 1.5 -year-old fish was close to 0 , whereas body length and condition showed negative correlation. Estimation of genetic correlation was very similar to that of phenotypic correlation. The phenotypic and genetic correlations of body weight and body length in 2-year-old fish were moderate and positive. The phenotypic correlation between body weight, body length, and CF was low and negative, but the genetic correlation was high. The results are shown in Table 5. 


\begin{tabular}{|c|c|c|c|}
\hline & Weight & Length & $\mathrm{CF}$ \\
\hline Weight $_{(1 \text { year) }}$ & 1 & 0.923 & 0.838 \\
\hline Length & 0.92 & 1 & 0.8794 \\
\hline & 0.90 & 0.917 & \\
\hline Weight $_{(1,5 \text { year) }}$ & 1 & 0.22 & 0.0646 \\
\hline Length $(1.5$ year) & 0.53 & 1 & -0.223 \\
\hline & 0.51 & -0.43 & 1 \\
\hline $\begin{array}{l}\text { Weight } \\
\text { (2 vears) }\end{array}$ & 1 & 0.366 & -0.026 \\
\hline Length 2 years) & 0.31 & 1 & -0.1337 \\
\hline $\mathrm{CF}_{(2 \text { years })}$ & -0.908 & -1 & 1 \\
\hline
\end{tabular}

$\mathrm{CF}=$ condition factors

\section{Phenotypic and genetic tendency of all traits}

The annual phenotypic and genetic trends for body weight, body length, and $\mathrm{CF}$ are presented in Figures 1-3. Estimated phenotypic trends for all traits were relatively large $(\mathrm{P}<$ 0.05 ) and favorable. However, for each growth trait, certain regions had large and undesirable phenotypic trends.

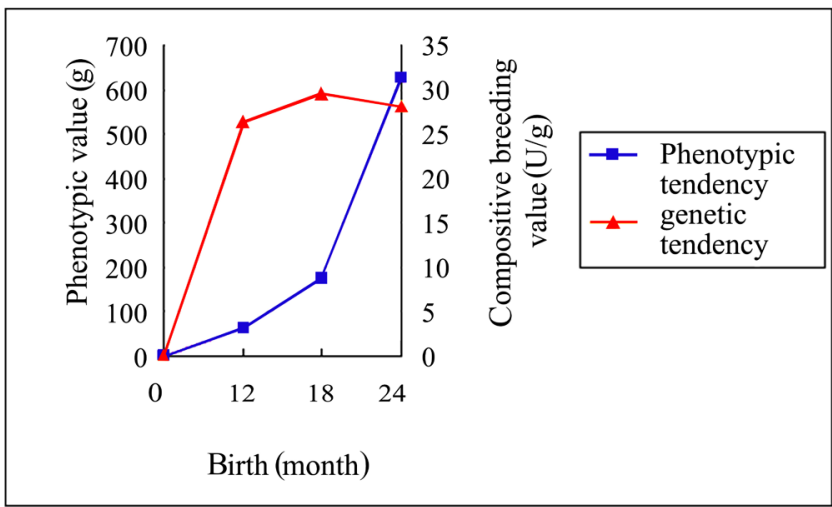

Figure 1. Phenotypic and genetic change tendency of body weight.

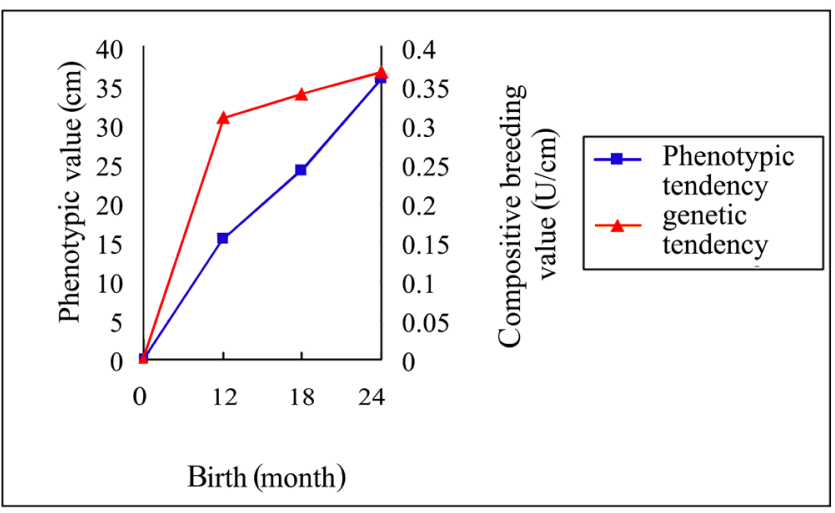

Figure 2. Phenotypic and genetic change tendency of body length. 


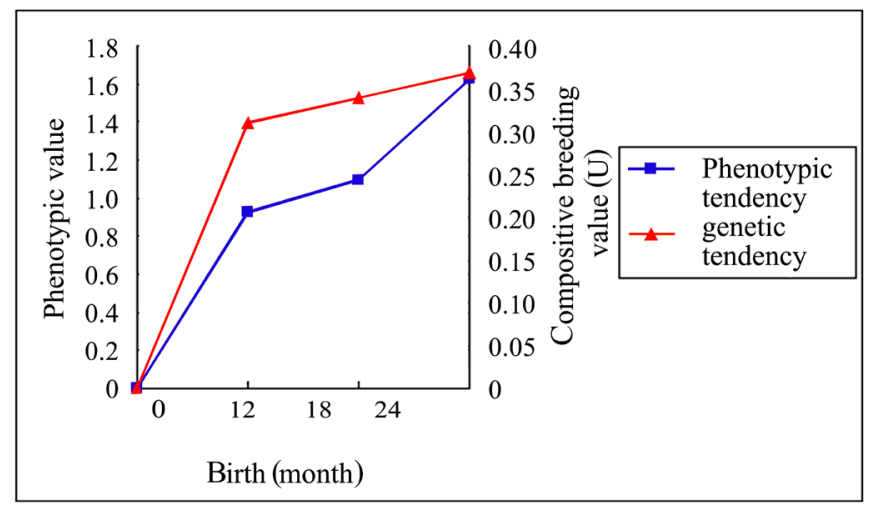

Figure 3. Phenotypic and genetic change tendency of condition factors.

In contrast to the phenotypic trends, all of the estimated genetic trends in both data sets were relatively small and sometimes undesirable (see Figures 1-3). Although some of the trends were desirable and significant, the magnitude of the change over time was of limited practical importance.

\section{DISCUSSION}

The genetic parameter of body weight estimated using the single-trait animal model showed moderate-to-high heritability estimates ranging from 0.2 to 0.45 . The heritability estimates of body length ranged from 0.27 to 0.6 . These results followed similar trends reported in other studies, which generally averaged 0.2-0.3 for Atlantic salmon aged 2-3 years (Gunnes and Gjedrem, 1978; Gjerde and Refstie, 1984; McKay, 1986; Gjerde, 1988; Gjerde and Schaeffer, 1989; Rye and Gjerde, 1996). The heritability for CF estimated at 0.35 in the present study was similar or slightly higher than that of previous reports in rainbow trout $\left(\mathrm{h}^{2}=0.19-0.45\right)$ (McKay, 1986; Kause et al., 2002). Furthermore, bidirectional mass selection for the body height:body length ratio in common carp has resulted in a strong selection response after one generation of selection, with a realized heritability of 0.33-0.47 (Ankorion et al., 1992). The magnitude of the calculated values from the present study tended to be smaller than those found in other studies. Although the reasons for these differences are unknown, multiple growout sites with various environmental conditions leading to additional environmental variance may have caused lower than expected heritability estimates. However, such site differences should have been largely accounted for by site-fixed effects in the model. Moreover, regarding expected environmental effects, the estimates may also have been influenced by factors that could not be recorded during these experiments, including genetic differences among populations (Roff and Moousseau, 1987; Roff, 1997, 2000), genotype-by-environment interactions (Stearns, 1992), sample errors in family assignment, and stage of sexual maturation.

Genetic correlations among the growth traits were similar in both multiple-trait analyses. Elvingson and Nilsson (1994) found that the largest genetic and environmental correlations are obtained between body weight and body length at 1.5-2.5 years. These correlations decreased as differences in weight and length increased with age. The genetic correlations 
between weight and CF were slightly negative to moderately positive at 2.5 years of age. These results were mostly in agreement with those of previous studies (McKay, 1986; Standal and Gjerde, 1987; Gjerde et al., 1994; Kause et al., 2002). Body weight, body length, and $\mathrm{CF}$ showed medium-to-high genetic correlation, in the range of 1.0-1.5 years indicating that exploiting the variation in early growth would be profitable if weight at 2.5 years were the trait of interest. However, late maturity is a desirable trait in many fish breeding programs (Gjerde, 1988; Crandell and Gall, 1993; Su et al., 1996). Although growth and age at maturity are interrelated, whether rapid growth induces maturation or maturation stimulates growth is unclear. We predict that strong selection for rapid growth advances the initiation of maturity as correlated with genetic change, which might further motivate fish breeders to select for late maturity. Although late maturity is genetically connected with slow growth, much variation accompanies this trend.

Significant positive direct trends for body weight and body length indicated effective selection for the improvement of these traits. The gains in body weight observed in the present study are similar to previously reported values (O'Flynn et al., 1999; Thodesen et al., 1999; Bolivar and Newkirk, 2002; Vandeputte et al., 2002). In a Finnish breeding program, genetic gains in weight ranged from 4.8 to $12.5 \%$ per generation. However, estimates of genetic progress showed that the trends for $\mathrm{CF}$ were not as well defined as those for performance traits because they were lower between 1.0 and 1.5 years. Thus, genetic trend estimates for the direct additive genetic values indicated that the currently used selection program has achieved favorable results.

In summary, our results elucidated the genetic parameters of growth traits in the breeding program for rainbow trout in China. Although they seemed to be the same as those for cultured rainbow trout in other countries, the results may be helpful in furthering the understanding of the genetic architecture of the phenotypic variation of growth traits in rainbow trout and may guide rainbow trout breeding practice in China.

\section{ACKNOWLEDGMENTS}

We acknowledge members of the rainbow trout breeding group at the Bohai cold-water fish experimental station affiliated with HRFRI for help in managing the fish and collecting the phenotypic data. Research supported by the National Science and Technology Support Project (\#2012BAD26B03-07), the Special Fund for Agro-Scientific Research in the Public Interest (\#201003055), and the Central-Level Non-Profit Scientific Research Institutes Special Funds (\#201110; \#201008).

\section{REFERENCES}

Ankorion Y, Moav R and Wohlfarth GW (1992). Bidirectional mass selection for body shape in common carp. Genet. Sel. Evol. 24: 43-52.

Boldman KG, Kriese LA, Van Vleck LD, Van Tassell CP, et al. (1995). A Manual for Use of MTDFREML. A Set of Programs to Obtain Estimates of Variances and Covariances [DRAFT]. U.S. Department of Agriculture, Agricultural Research Service, Washington, DC.

Bolivar R and Newkirk G (2002). Response to within family selection for body weight in Nile tilapia (Oreochromis niloticus) using a single-trait animal model. Aquaculture 204: 371-381.

Crandell P and Gall G (1993). The genetics of body weight and its effect on early maturity based on individually tagged rainbow trout (Oncorhynchus mykiss). Aquaculture 117: 77-93. 
Donaldson LR (1969). Marine Aquaculture. Oregon State University Press, 65-74.

Elvingson P and Nilsson J (1994). Phenotypic and genetic parameters of body and compositional traits in Arctic charr, Salvelinus alpinus. Aquac. Fish. Manag. 25: 677-685.

Food Agriculture Organization (2012). Aquaculture Production: Quantities 1950-2010 FISHSTAT Plus. Available at [http://www.fao.org/fi/statist/FISOFT/FISHPLUS.as]. Accessed June 15, 2012.

Gall GAE and Crandell PA (1992). The rainbow trout. Aquaculture 100: 1-10.

Gjedrem T (1983). Genetic variation in quantitative traits and selective breeding in fish and shellfish. Aquaculture 33: 51-72.

Gjerde B (1988). Complete diallel cross between six inbred groups of rainbow trout, Salmo gairdneri. Aquaculture 75: 71-87.

Gjedrem T (2000). Genetic improvement of cold-water fish species. Aquac. Res. 31: 25-33.

Gjerde B and Refstie T (1984). Complete diallel cross between five strains of Atlantic salmon. Livest. Prod. Sci. 11: 207226.

Gjerde B and Gjedrem T (1984). Estimates of phenotypic and genetic parameters for carcass traits in Atlantic salmon and rainbow trout. Aquaculture 36: 97-110.

Gjerde B and Schaeffer LR (1989). Body traits in rainbow trout: II. Estimates of heritability and of phenotypic and genetic correlations. Aquaculture 80: 25-44.

Gjerde B, Simianer H and Refstie T (1994). Estimates of genetic and phenotypic parameters for body weight, growth rate, and sexual maturity in Atlantic salmon. Livest. Prod. Sci. 38: 133-143.

Griffing B (1956). Concept of general and specific combining ability in relation to diallel crossing systems. Aust. J. Biol. Sci. 9: 463-493.

Gunnes K and Gjedrem T (1978). Selection experiments with salmon: IV. Growth of Atlantic salmon during two years in the sea. Aquaculture 15: 19-33.

Janhunen M, Kause A, Vehviläinen H and Järvisalo O (2012). Genetics of microenvironmental sensitivity of body weight in rainbow trout (Oncorhynchus mykiss) selected for improved growth. PLoS One 7: e38766.

Jensen J (2001). Genetic evaluation of dairy cattle using test-day models. J. Dairy Sci. 84: 2803-2812.

Kause A, Ritola O, Paananen T and Eskelinen U (2002). Coupling body weight and its composition: a quantitative genetic analysis in rainbow trout. Aquaculture 211: 65-79.

Kause AD, Tobin EA, Mantysaari SAM, Martin DF, et al. (2012). Genetic potential for simultaneous selection of growth and body composition in rainbow trout (Oncorhynchus mykiss) depends on the dietary protein and lipid content: phenotypic and genetic correlations on two diets. Aquaculture 271: 162-172.

McKay LR (1986). Genetic parameters of growth in rainbow trout Salmon, as a function of age and maturity. Aquaculture 58: 241-254.

O’Flynn FM, Bailey JK and Friars GW (1999). Responses to two generations of index selection in Atlantic salmon (Salmo salar). Aquaculture 173: 143-147.

Roff DA (1997). Evolutionary Quantitative Genetics. Chapman and Hall, International Thompson Publishing, Toronto.

Roff DA (2000). Trade-offs between growth and reproduction: an analysis of the quantitative genetic evidence. J. Evol. Biol. 13: 434-445.

Roff DA and Mousseau TA (1987). Quantitative genetics and fitness: lessons from Drosophila. Heredity 58: 103-118.

Rye M and Gjerde B (1996). Phenotypic and genetic parameters of body composition traits and flesh color in Atlantic salmon, Salmo salar L. Aquac. Res. 27: 121-133.

Sae-Lim P, Komen H, Kause A, van Arendonk JA, et al. (2012). Defining desired genetic gains for rainbow trout breeding objective using analytic hierarchy process. J. Anim. Sci. 90: 1766-1776.

Standal M and Gjerde B (1987). Genetic variation in survival of Atlantic salmon during the sea-ranching period. Aquaculture 66: 197-207.

Stearns SC (1992). The Evolution of Life Histories. Oxford University Press, New York.

Su GS, Liljedahl LE and Gall GAE (1996). Effects of inbreeding on growth and reproductive traits in rainbow trout (Oncorhynchus mykiss). Aquaculture 142: 139-148.

Sun DJ and Wang BQ (2010). Aquaculture of Salmonids in China. Chin. J. Fish. 23: 56-62.

Thodesen J, Grisdale-Helland B, Helland SJ and Gjerde B (1999). Feed intake, growth and feed utilization of offspring from wild and selected Atlantic salmon (Salmo salar). Aquaculture 180: 237-246.

Vandeputte M, Quillet E and Chevassus B (2002). Early development and survival in brown trout (Salmo trutta fario L.): indirect effects of selection for growth rate and estimation of genetic parameters. Aquaculture 204: 435-445.

Wang ZM and Yang YH (2002). Cold Water Fish Culture in China. In: Cold Water Fisheries in the Trans-Himalayan Countries (Petr T and Swar DB, eds.). FAO Fisheries Technical Paper, Rome, 97-100. 